\title{
Consumer Confidence and Stock Markets: The Panel Causality Evidence
}

\author{
Chih-Chiang Hsu \\ Department of Economics, National Central University \\ No.300, Jhongda Rd., Jhongli City, Taoyuan County 32001, Taiwan (R.O.C.) \\ E-mail: cchsu@mgt.ncu.edu.tw \\ Hung-Yu Lin (Corresponding author) \\ Department of Economics, National Central University \\ No.300, Jhongda Rd., Jhongli City, Taoyuan County 32001, Taiwan (R.O.C.) \\ Tel: 886-3422-7151 ext.66314 E-mail: hylin@mgt.ncu.edu.tw \\ Jyun-Yi Wu \\ Department of Economics, National Central University \\ No.300, Jhongda Rd., Jhongli City, Taoyuan County 32001, Taiwan (R.O.C.) \\ E-mail: jywu@mgt.ncu.edu.tw \\ and \\ Commerce Development Research Institute \\ 3F, No 303, Sec. 1, Fu-Xing South Rd. Taipei 10665, Taiwan (R.O.C.) \\ E-mail: jywu@cdri.org.tw
}

Received: June 20, 2011

doi:10.5539/ijef.v3n6p91
Accepted: July 5, 2011

Published: November 1, 2011

URL: http://dx.doi.org/10.5539/ ijef.v3n6p91

\begin{abstract}
This paper uses a panel of country-level data to investigate the causal relationship between the consumer confidence index (CCI) and the stock market index (SMI). We apply the common correlated effects mean group (CCEMG) estimation of Pesaran (2006) to capture the cross-sectional dependence of our variables before examining this causal relationship. In the panel data analysis, we discover the two-way causality between the CCI and SMI. One of the ways is where stock returns Granger-cause the changes in the CCI. According to the information view of the CCI, this result is due to consumers regarding the stock returns as being the leading indicators of the future situation, regardless of whether they own the stocks or not. On the other hand, the changes in the CCI also Granger-cause the stock returns, the reason for this being attributable to the animal spirits view of consumers. When consumers believe in their own opinions, they will at the same time have strong confidence in and an optimistic attitude toward the future economic situation. Based on these conditions, consumers will invest more in the stock market.
\end{abstract}

Keywords: Consumer confidence, Cross-sectional dependence, Panel causality test

JEL Classification: C33; E21; G11

\section{Introduction}

The question as to whether consumer confidence stimulates various economic and financial variables or whether the reverse causation is at play has spurred a great deal of attention over the past two decades. Why does consumer confidence play an important role in macroeconomics? The first reason is based on the "information view" summarized by Throop (1992). Confidence measures include fundamental information regarding the current and future states of the economy. Another reason is "animal spirits" in that the consumer confidence may reflect the "subjective" state of mind of consumers that cannot be deduced from the economic variables.

The information view is related to the life-cycle permanent income hypothesis and the rational expectations permanent income hypothesis and is termed the conventional approach in the consumer confidence literature. For example, Carroll et al. (1994) state that consumer sentiment has a degree of explanatory power in predicting changes 
in household spending. Lemmon and Portniaguina (2006) argue that consumer confidence exhibits forecasting power for the returns on small stocks. Taylor and McNabb (2007) show that the consumer and business confidence indicators can constitute a useful tool for identifying discrete turning points in the business cycle for four European economies.

The existing literature also provides some evidence to support the animal spirits view, with studies like Guo and Sturzenegger (1998) having shown that their models rely on the self-fulfilling belief that influences the agents' desire to consume and elicit strong labor supply response. In financial studies, investors are subject to sentiment. Sentiment is a belief about future cash flows and investment risks that is not justified by the facts at hand. So, when sentiment increases, we can expect such speculative stocks to have higher returns as provided by Backer and Wurgler (2006). Lee et al. (2002) suggest that sentiment is a significant factor in explaining equity excess returns and conditional volatility. In particular, their results show that sentiment is a priced risk factor.

In this paper we investigate the causal relationship between stock market indexes (henceforth SMI) and consumer confidence indexes (henceforth CCI) using a panel data set of 21 countries covering the period from January 1999 to December 2007. We employ the common correlated effects mean group (CCEMG) estimation suggested by Pesaran (2006) for the panel Granger-causality test. The advantage of the CCEMG approach is that it can tackle the problem of cross-sectional dependence and provide more reliable inference. Our empirical results show that stock returns Granger-cause changes in consumer confidence and vice versa. Possible reasons for the one-way causality from stock returns to the change in consumer confidence include the effect of wealth on consumption. The investors' income will, for instance, increase when stock markets are booming. Another reason is that the stock market is a leading indicator of future income and the economic situation. While these reasons are based on the information view of consumer confidence, another way in which Granger causality operates has previously been overlooked in the literature. The explanation for the direction of causality from the change in consumer confidence to the returns of stock markets is animal spirits. This means that autonomous changes in consumer beliefs toward economic conditions and future consumption expenses have causal effects on overall economic behavior.

The remainder of this paper is organized as follows. The next section describes the econometric methodologies employed. Section 3 discusses the data and empirical results, while the final section provides the main conclusions.

\section{Econometric Framework}

A panel Granger-causality framework can investigate the causal relationship between two economic variables of interest to take into account the cross-sectional information. The use of traditional estimators such as the fixed-effects (FE) and the mean-group (MG) estimators will result in potential bias when ignoring the cross-sectional dependence; see Pesaran (2006) and Petersen (2009). In the following context, we consider the cross-sectional dependence by means of panel unit root tests, panel cointegration tests, and the use of the panel estimation method. Finally, we apply the panel Granger-causality framework to study the relationship between the $\mathrm{CCI}$ and SMI.

\subsection{Panel Unit Root and Cointegration Tests}

Since the Granger-causality test requires stationary data, our resulting data need to be tested for the presence of unit roots. We use the panel unit root tests of Pesaran (2007) and Moon and Perron (2004) to account for the cross-sectional dependence arising from common factors. Pesaran (2007) models the cross-sectional dependence through a single common factor and proposes the unit root test by running the ADF regression with the lagged cross-sectional mean and its first-difference. Moon and Perron (2004) propose estimating unknown common factors using the principal components method and suggest pooling defactored data to construct two unit root tests, $t_{a}{ }^{*}$ and $t_{b}^{*}$.

To investigate the existence of a long-run relationship between the CCI and SMI, we consider two types of panel cointegration tests that account for cross dependence. Pedroni (2004) proposes residual-based tests for the null of no panel cointegration. Westerlund (2007) develops the error correction-based tests to check for the presence of panel cointegration under cross dependence. Both statistics of Pedroni (2004) and Westerlund (2007) can permit heterogeneous fixed effects, have short-run dynamics and have limiting normal distributions under the null of no cointegration.

\subsection{Panel Estimation and the Granger-Causality Test}

We use the common correlated effects (CCE) estimators of Pesaran (2006) to solve the estimation problem of ignoring the cross-sectional dependence. Consider the following time-stationary representation of $C C I_{i t}$ and $S M I_{i t}$, 


$$
\begin{gathered}
\Delta C C I_{i t}=\boldsymbol{\alpha}_{c i} \mathbf{d}_{t}+\sum_{k=1}^{p} \beta_{s i}^{(k)} \Delta S M I_{i, t-k}+\sum_{k=1}^{p} \gamma_{c i}^{(k)} \Delta C C I_{i, t-k}+e_{c, i t}, \\
\Delta S M I_{i t}=\boldsymbol{\alpha}_{s i} \mathbf{d}_{t}+\sum_{k=1}^{p} \beta_{c i}^{(k)} \Delta C C I_{i, t-k}+\sum_{k=1}^{p} \gamma_{s i}^{(k)} \Delta S M I_{i, t-k}+e_{s, i t},
\end{gathered}
$$

where $\mathbf{d}_{t}$ is a vector of observed common effects. The disturbance term, $e_{h, i}, h=c, s$ has the following structure:

$$
e_{h, i t}=\boldsymbol{\delta}_{h i}^{\prime} \mathbf{f}_{t}+\varepsilon_{h, i t},
$$

in which $\mathbf{f}_{t}$ is a vector of unobserved common factors, $\boldsymbol{\delta}_{h i}$ is a vector of factor loadings and $\varepsilon_{h, i t}$ denotes the individual-specific error. We assume that the unobserved common factors $\mathbf{f}_{t}$ are covariance stationary and serially uncorrelated.

Let $y_{i t}=C C I_{i t}$ or $S M I_{i t}$. By combining (1) - (3), we can construct the following system of equations (cf. Pesaran, 2006)

$$
\boldsymbol{z}_{i t}=\left(\begin{array}{c}
y_{i t} \\
\mathbf{x}_{i, t-k}
\end{array}\right)=\mathbf{B}_{i}^{\prime} \mathbf{d}_{t}+\mathbf{C}_{i}^{\prime} \mathbf{f}_{t}+\epsilon_{i t}
$$

where $\mathbf{x}_{i, t-k}=\left(S M I_{i, t-1, \ldots ;}, S M I_{i, t-p}, \quad C C I_{i, t-1}, \ldots, \quad C C I_{i, t-p}\right)^{\prime}$. To deal properly with the residual cross-sectional dependence, Pesaran (2006) suggests using a three-step procedure to estimate the coefficients in(1) and (2). (Note 1) First, we consider the cross-sectional average of $\boldsymbol{z}_{i t}$, defined by $\overline{\mathbf{z}}=\sum_{j=1}^{N} w_{j} \mathbf{z}_{j t}$, and $\overline{\mathbf{z}}=\overline{\mathbf{B}}^{\prime} \mathbf{d}_{t}+\overline{\mathbf{C}}^{\prime} \mathbf{f}_{t}+\overline{\boldsymbol{\epsilon}}{ }_{t} . \overline{\mathbf{B}}, \overline{\mathbf{C}}$, and $\overline{\boldsymbol{\epsilon}}_{t}$ have similar definitions as $\overline{\mathbf{z}}$. Then, we can define $\overline{\mathbf{h}}=\left(\mathbf{d}_{t}^{\prime}, \overline{\mathbf{z}}^{\prime}\right)^{\prime}$ as observed proxies for unobserved factors $\mathbf{f}_{t}$. It turns out that the $\overline{\mathbf{h}}$ are sufficient for asymptotically filtering out the effects of the unobserved common factor. Finally, the individual slope coefficients of interest, ${ }_{i}$ and ${ }_{i}$, can be estimated by augmenting the OLS regressions of $y_{i t}$ on $\mathbf{x}_{i, t-k}$ with $\overline{\mathbf{h}}$ to obtain the CCE estimators, $\hat{\mathbf{b}}_{\text {cce }}$. The CCEMG estimator $\left(\hat{b}_{c c e m g}\right)$ is a simple average of the individual CCE estimators,

$$
\hat{b}_{\text {ccemg }}=\frac{1}{N} \sum_{i=1}^{N} \hat{\mathbf{b}}_{\text {cce }} .
$$

Pesaran (2006) shows that the CCE and CCEMG estimators are consistent as $N, T \rightarrow \infty$, jointly.

Hurlin and Venet (2001) propose an extension of the Granger-causality test which allows for the use of time series and cross-sectional data to test for the causal relationship. In the Hurlin and Venet (2001) setting, to test the homogeneous non-causality hypothesis of equation (1), the corresponding test is given by:

$$
\begin{aligned}
& H_{0}: \beta_{s i}^{(k)}=0, \quad \text { for } i=1, \ldots, N . \quad \text { for } k=1, \ldots, p, \\
& H_{1}: \exists(i, k) / \beta_{s i}^{(k)} \neq 0, \quad \text { for } i=1, \ldots, N . \quad \text { for } k=1, \ldots, p .
\end{aligned}
$$

Similarly, the analogical hypothesis of equation (2) can be tested. Based on the residuals of the CCE regressions, we can compute the following likelihood-ratio statistic:

$$
F=\frac{\left(R S S_{r}-R S S_{u}\right) / N p}{R S S_{u} /(N T-N(1+p)-p)}
$$

where $N T$ equals the total sample, and $R_{S S}\left(R S S_{r}\right)$ corresponds to the unrestricted (restricted) sum of squared residuals. (Note 2) If we reject the null hypothesis, in which case the lagged terms of changes in the SMI (CCI) belong in the regression, this means that the stock returns (changes in the CCI) cause changes in the CCI (the stock returns) in the panel data.

\section{Empirical Results}

\subsection{Data and Diagnostic Tests}

We employ monthly data for a panel of 21 countries from 1999 to 2007 in order to analyze the causal relationship between the CCI and SMI. (Note 3) Our CCI data are consumer opinion survey data published in OECD's monthly Main Economic Indicators. Consumer opinion surveys are provided to obtain qualitative information for use in monitoring the current economic situation and in forecasting future consumption. Definitions and calculations of national confidence indicators are gathered according to national statistical institutes or other government agencies. 
Generally speaking, the questions asked about the $\mathrm{CCI}$ are classified as financial positions (consumption), economic situations, and savings behavior (income). In particular, in order to fit in with different countries' economic circumstances, specific questions listed in the consumer survey may vary slightly. Furthermore, all stock market index data (Datastream total market index) are collected and calculated by Datastream, see Datastream (2008).

To test for the panel Granger causality between the CCI and SMI, it is required that these two variables be stationary. The panel unit root test results of the CCI and SMI are shown in Table 1. Both tests of Pesaran (2007) and Moon and Perron (2004) detect the first differences of the CCI and SMI as rejecting the null hypothesis of no panel unit root. (Note 4) In other words, our data are stationary in relation to the first differences.

To confront the issue of the long-run equilibrium in panel data, we adopt the panel cointegration tests of Pedroni (2004) and Westerlund (2007). We use a bootstrap procedure to handle data characterized by cross-sectional dependence in Westerlund (2007). As shown in Table 2, all of the cointegration tests result in the nonrejection of the null hypothesis of no cointegration. This means that there is no long-run relationship between the stock index and the consumer confidence. These test results are in line with the findings of Jansen and Nahuis (2003).

\subsection{Panel Granger-Causality Results}

One careful consideration in investigating the causality nexus between the CCI and SMI is the existence of cross-sectional dependence across countries. We mainly estimate the multifactor residual model proposed by Pesaran (2006) and then test for the panel Granger causality. For comparison purposes, we present three different panel estimators, including two estimators without cross-sectional dependence (MG and FE) and the other one with cross-sectional dependence (CCEMG). The number of lags included in (1) and (2) is determined by minimizing the Schwarz criterion. (Note 5)

As shown in Panel A of Table 3, based on the MG and FE results, no less than two of the five periods of the lagged stock returns have an impact on changes in the CCI. Due to the importance of cross-sectional dependence, we discover that our CCEMG results display the impact of the fifth period of lagged stock returns on changes in the $\mathrm{CCI}$ at a statistically significant level.

Generally speaking, there are two views regarding the role of the confidence index in macroeconomic analysis. One view, the information view, is that the confidence index mainly measures the current and future economic situations. Our argument regarding the CCEMG results in Panel A of Table 3 is as follows. We focus on two aspects by which movements in stock returns could affect consumer confidence. The first one is that when the stock market is booming, the investors' income will increase because investors make a profit from the stock market. They will tend to purchase goods and services in the future. That is to say, the consumers exhibit optimism toward future economic conditions. As we know, this effect is related to the traditional wealth effect on consumption. The second one, which is more important, is that consumers regard stock returns as a leading indicator of future income and the economic situation. In the empirical literature, Otoo (1999) uses aggregate U.S. data and finds that movements in consumer confidence and the stock market are strongly correlated and relevant tests reveal the impacts of stock returns on changes in consumer confidence. Furthermore, Jansen and Nahuis (2003) also support the view of Otoo (1999). They use 11 European countries and still conclude that stock returns Granger-cause the consumer confidence index through the confidence channel which is based on the leading indicator characteristic of stock prices.

In applying the above three estimation methods, by contrast, we study the effects of changes in the lagged terms of changes in the CCI and SMI on stock returns and the estimation results are shown in Panel B of Table 3. The estimation results of MG, FE, and CCEMG consistently reveal positive coefficients for one-period lagged changes in the CCI. This means that bigger changes in the lagged CCI will lead to higher stock returns.

We try to adopt the animal spirits view to analyze the role of consumer confidence. This means that autonomous changes in consumer beliefs toward economic conditions and future consumption expenses have causal effects on overall economic behavior. Our empirical results in Panel B of Table 3 support the above view. When consumers believe in their own opinions, they will in the meantime have strong confidence and an optimistic attitude toward the future business or investment situation. Thus, the consumer indicator will exhibit a rising trend. Based on positive expectations of future economic conditions, consumers will have the motivation to invest in the stock market. Therefore, the stock market will be booming and investors will have the potential to profit. In contrast to Jansen and Nahuis (2003), our CCEMG results indicate that the lagged terms of stock returns will still have an influence on current changes in the CCI. Here, we first try to use panel data information to estimate the possibility of cross-sectional dependence in studying the nexus among these two variables of interest. This is why we arrive at some different results from Jansen and Nahuis (2003).

The sentiment index can express people's feelings about the economy and their subsequent plans to make purchases. 
The index is becoming more useful for investors because it indicates whether consumers feel like spending money, whereas most quantitative economic variables cannot capture the change in consumer sentiment. We try to use the animal spirit view to explain the result. In the financial literature, a number of recent papers have placed emphasis on the importance of the sentiment index. They discuss the relationship between the sentiment index and various asset returns; see Fisher and Statman (2003) and Kalotay et al. (2007).

Last, but not least, we investigate the relationship between the CCI and SMI by not only using the CCEMG estimation, but also by using the panel Granger-causality test. As indicated by the $F$-statistics in Table 4, the causal relationships between the CCI and SMI in our panel data are roughly consistent with the results of our estimation. We find that two-way causal relationships exist between the CCI and SMI. As for the Granger-causality tests used in the CCEMG estimation, we observe that movements in the stock market positively affect the changes in consumer confidence, whereas the Granger causality is found to run from the changes in consumer confidence and the stock market. The reason why we support the result is that the information view and animal spirits view can explain the two-way causal relationship clearly. In addition, the results of the Granger-causality test on changes in consumer confidence to stock returns can be particularly explained by the animal spirits view.

\section{Conclusions}

This paper aims to investigate the causal relationship between consumer confidence and the stock price indexes. In globalization, news can easily be transmitted from one country to another. This may lead to each country's consumer confidence and stock markets having similar patterns. Consumer confidence and stock market prices are by construction strongly cross-sectionally correlated and we allow for persistent cross-sectional dependence by allowing for common factors. According to this characteristic of the data, the traditional inference of panel data might be biased. Therefore, we take careful account of this problem caused by cross-sectional dependence in our empirical study.

As for the Granger-causality test, our empirical results show that stock returns Granger-cause the changes in the CCI using the CCEMG of Pesaran (2006). Based on the belief that investors' income will increase and that stock returns are the leading indicators, consumers will maintain a positive attitude toward future economic conditions. Furthermore, we find the Granger causality running from the change in consumer confidence and stock returns. Most studies ignore this effect. The explanation is that if consumers believe that future economic conditions will be good, they will then tend to invest in the stock market.

\section{References}

Backer, M., \& Wurgler, J. (2006). Investor Sentiment and the Cross-Section of Stock Returns. Journal of Finance. 61 (4), 1645-1680, http://dx.doi.org/10.1111/j.1540-6261.2006.00885.x

Carroll, C. D., Fuhrer, J. C., \& Wilcox, D. W. (1994). Does Consumer Sentiment Forecast Household Spending? If So, Why? American Economic Review. 84 (5), 1397-1408.

Datastream (2008). Datastream Global Equity Indices: User Guide. [Online] Available: $\mathrm{http} / /$ thomsonreuters.com/content/financial/pdf/i_and_a/indices/datastream_global_equity_manual.pdf

Fisher, K. L., \& Statman, M. (2003). Consumer Confidence and Stock Returns. Journal of Portfolio Management. 30 (1), 115-127, http://dx.doi.org/10.3905/jpm.2003.319925

Guo, J.-T., \& Sturzenegger, F. (1998). Crazy Explanations of International Business Cycles. International Economic Review. 39 (1), 111-133, http://dx.doi.org/10.2307/2527233

Hurlin, C., \& Venet, B. (2001). Granger Causality Tests in Panel Data Models with Fixed Coefficients. EURIsCO Working Paper.

Jansen, W. J., \& Nahuis, N. J. (2003). The Stock Market and Consumer Confidence: European Evidence. Economics Letters. 79 (1), 89-98, http://dx.doi.org/10.1016/S0165-1765(02)00292-6

Kalotay, E., \& Gray, P.; Sin, S. (2007). Consumer Expectations and Short-Horizon Return Predictability. Journal of Banking and Finance. 31 (10), 3102-3124, http://dx.doi.org/10.1016/j.jbankfin.2006.11.017

Lee, W. Y., Jiang, C. X., \& Indro, D. C. (2002). Stock Market Volatility, Excess Returns, and the Role of Investor Sentiment. Journal of Banking and Finance. 26 (12), 2277-2299, http://dx.doi.org/10.1016/S0378-4266(01)00202-3

Lemmon, M., \& Portniaguina, E. (2006). Consumer Confidence and Asset Prices: Some Empirical Evidence. Review of Financial Studies. 19 (4), 1499-1529, http://dx.doi.org/10.1093/rfs/hhj038

Moon, H. R., \& Perron, B. (2004). Testing for a Unit Root in Panels with Dynamic Factors. Journal of Econometrics. 122 (1), 81-126, http://dx.doi.org/10.1016/j.jeconom.2003.10.020 
Otoo, M. W. (1999). Consumer Sentiment and the Stock Market. Finance and Economics Discussion Series.

Pedroni, P. (2004). Panel Cointegration: Asymptotic and Finite Sample Properties of Pooled Time Series Tests with an Application to the PPP Hypothesis. Econometric Theory. 20(3), 597-625, http://dx.doi.org/10.1017/S0266466604203073

Pesaran, M. H. (2006). Estimation and Inference in Large Heterogeneous Panels with a Multifactor Error Structure. Econometrica. 74 (4), 967-1012, http://dx.doi.org/10.1111/j.1468-0262.2006.00692.x

Pesaran, M. H. (2007). A Simple Panel Unit Root Test in the Presence of Cross-section Dependence. Journal of Applied Econometrics. 22 (2), 265-312, http://dx.doi.org/10.1002/jae.951

Petersen, M. A. (2009). Estimating Standard Errors in Finance Panel Data Sets: Comparing Approaches. Review of Financial Studies. 22 (1), 435-480, http://dx.doi.org/10.1093/rfs/hhn053

Taylor, K., \& McNabb, R. (2007). Business Cycles and the Role of Confidence: Evidence for Europe. Oxford Bulletin of Economics and Statistics. 69 (2), 185-208, http://dx.doi.org/10.1111/j.1468-0084.2007.00472.x

Throop, A. W. (1992). Consumer Sentiment: Its Causes and Effects. Federal Reserve Bank of San Francisco Economic Review. 1, 35-60.

Westerlund, J. (2007). Testing for Error Correction in Panel Data. Oxford Bulletin of Economics and Statistics. 69 (6), 709-748, http://dx.doi.org/10.1111/j.1468-0084.2007.00477.x

\section{Notes}

Note 1. Pesaran (2006) discusses the CCE estimation in nondynamic models, which can be extended to panel regressions with lagged dependent regressors and panel vector autoregressions; see Pesaran (2006, p.1001).

Note 2. Under the regularity conditions and the consistency of the CCE estimators, Pesaran (2006) shows that the residuals of the CCE regressions can provide consistent estimates of $e_{h, i t}$ in the multifactor model (1) - (3) to obtain proper variance estimators and testing statistics.

Note 3. Countries in our sample include: Austria, Belgium, Canada, China, the Czech Republic, Denmark, Finland, France, Germany, Greece, Hungary, Ireland, Italy, Japan, Korea, the Netherlands, Portugal, Spain, Sweden, the United Kingdom, and the United States.

Note 4. In the case of the panel unit root tests proposed by Moon and Perron (2004), we report the test statistics for different values of $K$ (the numbers of factors); $K=1,3,6$.

Note 5. The maximum value of the lag length is set as 12 . For equation (2), the optimal lag length is 6 , which is the same for all estimation methods. For equation (1), the optimal lag length of the FE (MG and CCEMG) method is $5(6)$

Table 1. Panel unit root test results

\begin{tabular}{|c|c|c|c|c|c|c|c|}
\hline & \multirow[t]{3}{*}{ Pesaran(2007) } & \multicolumn{6}{|c|}{ Moon and Perron(2004) } \\
\hline & & \multicolumn{2}{|c|}{$K=1$} & \multicolumn{2}{|c|}{$K=3$} & \multicolumn{2}{|c|}{$K=6$} \\
\hline & & $t_{a}{ }^{*}$ & $t_{b}{ }^{*}$ & $t_{a}^{*}$ & $t_{b}{ }^{*}$ & $t_{a}^{*}$ & $t_{b}{ }^{*}$ \\
\hline \multicolumn{8}{|c|}{ Level } \\
\hline $\mathrm{CCI}$ & -2.242 & 0.475 & 0.295 & 0.816 & 0.543 & 0.727 & 0.540 \\
\hline SMI & -2.585 & -2.135 & -2.010 & -1.387 & -1.185 & 1.539 & 1.285 \\
\hline \multicolumn{8}{|c|}{ Difference } \\
\hline $\mathrm{CCI}$ & $-4.232^{* * *}$ & $-9.614^{* * *}$ & $-3.892^{* * *}$ & $-18.418^{* * *}$ & $-7.679^{* * *}$ & $-18.388^{* * *}$ & $-7.922^{* * *}$ \\
\hline SMI & $-3.848^{* * *}$ & $-78.779^{* * *}$ & $-29.789^{* * *}$ & $-100.043^{* * *}$ & $-38.979^{* * *}$ & $-85.710^{* * *}$ & $-31.887^{* * *}$ \\
\hline
\end{tabular}

1. *** denotes rejection of the null of the panel unit root hypothesis at the $1 \%$ significance level.

2. $K$ represents the different numbers of factors. 
Table 2. Panel cointegration test results

\begin{tabular}{lcc}
\hline & Statistic & $P$-value \\
\hline Panel A: Pedroni (2004) & & \\
Panel v & -2.524 & 0.994 \\
Panel rho & 2.269 & 0.988 \\
Panel PP & 2.014 & 0.978 \\
Panel ADF & 2.000 & 0.997 \\
Group rho & 3.292 & 1.000 \\
Group PP & 3.259 & 0.999 \\
Group ADF & 2.940 & 0.998 \\
\hline Panel B: Westerlund (2007) & & \\
Panel $\tau$ & -11.817 & 0.250 \\
Panel $\alpha$ & -18.485 & 0.384 \\
Group $\tau$ & -2.648 & 0.402 \\
Group $\alpha$ & -23.126 & 0.680 \\
\hline
\end{tabular}

1. The null hypothesis is no panel cointegration.

2. The $P$-values in Westerlund (2007) are for a one-sided test based on the bootstrapped distribution. We use 500 bootstrap replications.

Table 3. Panel estimation results

\begin{tabular}{|c|c|c|c|c|c|c|}
\hline & \multicolumn{2}{|l|}{ MG } & \multicolumn{2}{|l|}{ FE } & \multicolumn{2}{|l|}{ CCEMG } \\
\hline & coeff. & s.e. & coeff. & s.e. & coeff. & s.e. \\
\hline \multicolumn{7}{|c|}{ Panel A: Dependent variable $=\triangle C C I$} \\
\hline$\Delta S M I_{t-1}$ & 0.002 & $(0.001)$ & 0.003 & $(0.002)$ & 0.001 & $(0.002)$ \\
\hline$\Delta S M I_{t-2}$ & -0.001 & $(0.001)$ & 0.001 & $(0.002)$ & $-0.005^{* * *}$ & $(0.002)$ \\
\hline$\Delta S M I_{t-3}$ & $0.004^{* * *}$ & $(0.001)$ & 0.002 & $(0.002)$ & 0.001 & $(0.002)$ \\
\hline$\Delta S M I_{t-4}$ & $0.006^{* * *}$ & $(0.001)$ & $0.003^{* * *}$ & $(0.001)$ & 0.002 & $(0.001)$ \\
\hline$\Delta S M I_{t-5}$ & $0.004^{* * *}$ & $(0.001)$ & $0.005^{* * *}$ & $(0.002)$ & $0.006^{* * *}$ & $(0.002)$ \\
\hline$\triangle S M I_{t-6}$ & 0.001 & $(0.001)$ & -- & $\left(\begin{array}{ll}(- & \end{array}\right)$ & -0.001 & $(0.002)$ \\
\hline$\triangle C C I_{t-1}$ & $0.907^{* * *}$ & $(0.089)$ & $0.850^{* * *}$ & $(0.078)$ & $0.804^{* * *}$ & $(0.090)$ \\
\hline$\triangle C C I_{t-2}$ & -0.326 & $(0.185)$ & -0.235 & $(0.184)$ & -0.318 & $(0.172)$ \\
\hline$\Delta C C I_{t-3}$ & -0.084 & $(0.214)$ & $-0.324^{* * *}$ & $(0.136)$ & -0.067 & $(0.200)$ \\
\hline$\triangle C C I_{t-4}$ & -0.070 & $(0.150)$ & $0.351^{* * *}$ & $(0.087)$ & -0.088 & $(0.139)$ \\
\hline$\Delta C C I_{t-5}$ & $0.216^{* * *}$ & $(0.071)$ & $-0.197^{* * *}$ & $(0.087)$ & $0.177^{* * *}$ & $(0.072)$ \\
\hline$\Delta C C I_{t-6}$ & $-0.218^{* * *}$ & $(0.025)$ & -- & $\left(\begin{array}{ll}(-- \\
)\end{array}\right.$ & $-0.179^{* * *}$ & $(0.029)$ \\
\hline \multicolumn{7}{|c|}{ Panel B: Dependent variable $=\Delta S M I$} \\
\hline$\Delta C C I_{t-1}$ & $3.011^{* * *}$ & $(0.629)$ & $2.205^{* * *}$ & $(0.795)$ & $1.401^{* * *}$ & $(0.550)$ \\
\hline$\Delta C C I_{t-2}$ & -1.754 & $(0.915)$ & -0.639 & $(0.618)$ & -0.989 & $(0.572)$ \\
\hline$\Delta C C I_{t-3}$ & 1.776 & $(0.985)$ & 0.016 & $(0.666)$ & 0.425 & $(0.454)$ \\
\hline$\Delta C C I_{t-4}$ & -0.781 & (1.157) & 0.618 & $(0.643)$ & -0.074 & $(0.728)$ \\
\hline$\Delta C C I_{t-5}$ & 0.496 & $(0.929)$ & -0.226 & $(0.439)$ & 0.201 & $(0.617)$ \\
\hline$\triangle C C I_{t-6}$ & -0.761 & $(0.697)$ & -0.533 & $(0.334)$ & -0.181 & $(0.325)$ \\
\hline$\Delta S M I_{t-1}$ & -0.017 & $(0.024)$ & 0.059 & $(0.038)$ & -0.001 & $(0.033)$ \\
\hline$\Delta S M I_{t-2}$ & -0.008 & $(0.027)$ & -0.004 & $(0.032)$ & -0.048 & $(0.028)$ \\
\hline$\Delta S M I_{t-3}$ & 0.019 & $(0.019)$ & -0.000 & $(0.028)$ & -0.001 & $(0.030)$ \\
\hline$\Delta S M I_{t-4}$ & -0.032 & $(0.024)$ & $-0.047^{* * *}$ & $(0.023)$ & -0.021 & $(0.026)$ \\
\hline$\Delta S M I_{t-5}$ & $0.048^{* * *}$ & $(0.016)$ & 0.031 & $(0.025)$ & 0.038 & $(0.024)$ \\
\hline$\Delta S M I_{t-6}$ & $0.092^{* * *}$ & $(0.020)$ & 0.090 & $(0.029)$ & 0.002 & $(0.026)$ \\
\hline
\end{tabular}

1.** indicates that the estimates are significant at the $5 \%$ level. $\quad * * *$ indicates that the estimates are significant at the $1 \%$ level.

2. The constant term is not reported. 
Table 4. Panel Granger-causality test results

\begin{tabular}{lcc}
\hline & $\Delta S M I$ to $\triangle C C I$ & $\Delta C C I$ to $\triangle S M I$ \\
\hline MG & $0.975^{b}$ & $1.765^{b^{* *}}$ \\
CCEMG & $0.254^{a}$ & $0.453^{b}$ \\
\hline
\end{tabular}

1. a. The lag length is 5 . The $5 \%(1 \%)$ critical value for $F(100, \infty)$ is $1.26(1.38)$

b. The lag length is 6 . The $5 \%(1 \%)$ critical value for $F(120, \infty)$ is $1.23(1.32)$.

2. ** indicates that the estimates are significant at the $5 \%$ level.

*** indicates that the estimates are significant at the $1 \%$ level. 